\title{
Eradication of Helicobacter pylori and use of antisecretory drugs: population based cohort study
}

\author{
Annmarie Lassen, Jesper Hallas, Ove B Schaffalitzky de Muckadell
}

Helicobacter pylori is an important risk factor for peptic ulcers. If infection with $H$ pylor $i$ is cured, ulcers associated with $H$ pylori do not recur. An $H$ pylori "test and treat" strategy for patients with peptic ulcers having long term antisecretory treatment has been suggested, in the hope that eradicating $H$ pylor $i$ would curtail the rising use of antiulcer drugs. ${ }^{12}$ We describe the long term effect of eradicating H pylori on the use of antiulcer medication in a population of patients with peptic ulcers.

\section{Participants, methods, and results}

We included all patients in the Danish county of Funen (population 470000 ) who redeemed their first prescription for eradicating $H$ pylori between 1 January 1992 and 31 December 1996 and who had uncomplicated peptic ulcers endoscopically verified before or at the date of redeeming this prescription.

We drew data on gastroscopically and endoscopically verified diagnoses of peptic ulcers (from 1 January 1974) and on prescriptions of antisecretory drugs and treatment for eradicating H pylori (1 January 1991 to 31 December 1997) from comprehensive population based databases and linked the data by using mutual identifiers. ${ }^{3}{ }^{4}$ Treatment for eradicating $H$ pylori was a proton pump inhibitor or $\mathrm{H}_{2}$ receptor antagonist in combination with at least two antibiotics (amoxicilline, clarithromycin, metronidazole, tetracycline, or tinidazole). Long term use of antisecretory drugs $\left(\mathrm{H}_{2}\right.$ receptor antagonists and proton pump inhibitors) was 56 defined daily doses or more within a year. We did not include standard antisecretory drugs for curing ulcers and for eradicating $H$ pylori. We followed up all patients until they died, moved away from the county, or until 31 December 1997, whichever was soonest.

Of all 2099 users of drugs for eradicating $H$ pylori, 709 had a diagnosis of duodenal ulcer and 470 of gastric ulcer. In the analysis, we included the 155 patients with both duodenal and gastric ulcers as having duodenal ulcers. The patients' mean age was 57 (SD 18) years, and $59 \%$ were men. Follow up was at a median 5.5 years before and 2.2 years after redemption of the first prescription for eradicating $H$ pylori.

One year after eradication of $H$ pylori, 430/1024 $(42 \%)$ of the patients were taking antisecretory drugs long term. Using multivariate logistic regression, we found that long term use of antisecretory drugs after eradication of $H$ pylori was related to long term use of antisecretory drugs during the last year before eradication of $H$ pylori (odds ratio 2.1; 95\% confidence interval 1.6 to 2.8$)$, the presence of esophagitis $(3.1 ; 2.0$ to $4.7)$, being older than $60(1.8 ; 1.4$ to 2.4$)$, and to calendar years $(1.2 ; 1.1$ to 1.4$)$, but not to whether the ulcer was duodenal or gastric $(1.1 ; 0.8$ to 1.5$)$ or to use of aspirin or non-steroidal anti-inflammatory drug $(0.7 ; 0.5$ to 1.1$)$.

In the 453 patients taking antisecretory drugs long term in the year before eradication of $H$ pylori, mean

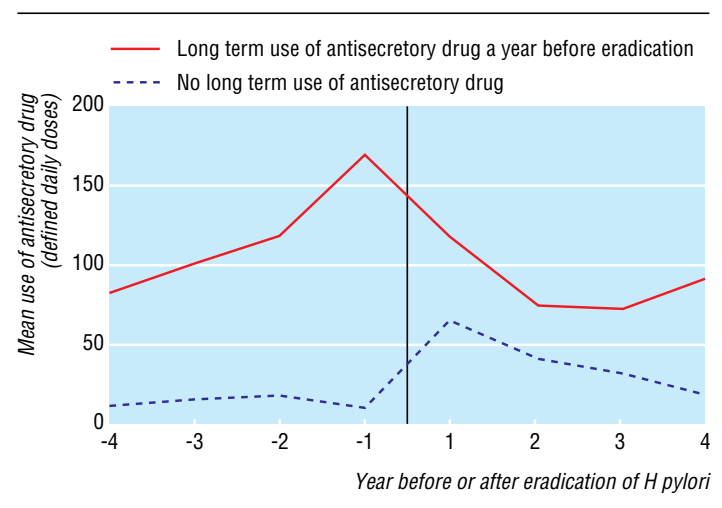

Mean use of antisecretory drugs before and after eradication of $H$ pylori (vertical line) in patients with uncomplicated peptic ulcers

use decreased by $24 \%$ from 119 to 91 defined daily doses for each patient after eradication of $H$ pylori (difference $-28,95 \%$ confidence interval -8 to -49 ; $\mathrm{P}=0.008$, cluster analysis) (figure). Conversely, in the 571 patients not taking antisecretory drugs long term in the year before eradication of $H$ pylori, mean use increased from 15 to 41 defined daily doses for each patient $(26,16$ to $35 ; \mathrm{P}<0.001)$.

\section{Comment}

Many patients with ulcers continue to take antisecretory drugs after eradication of $H$ pylori. Reasons for continuing use of antisecretory drugs are unknown but may include persistent reflux or dyspeptic symptoms in spite of effective eradication of $H$ pylori. ${ }^{5}$ In patients with peptic ulcers on long term treatment with antisecretory drugs, use of antisecretory drugs was $24 \%$ lower after eradication of $H$ pylori.

Contributors: AL was the principal investigator dealing with data management and analysis. AL and JH linked data from different registers. All investigators designed the study and wrote the paper. AL is guarantor.

Funding: National Research Agency, Denmark, and Institute of Clinical Research, University of Southern Denmark, Odense, Denmark.

Competing interests: OBSdeM has received research funding from AstraZeneca and from Nycomed who both produce proton pump inhibitors. OBSdeM, JH, and AL have each received $£ 500$ for speaking at an AstraZeneca symposium.

Ethical approval: Danish Data Protection Agency.

1 Malfertheiner P, Megraud F, O'Morain C, Hungin AP, Jones R, Axon A, et al. Current concepts in the management of Helicobacter pylori infection: the Mastricht 2-2000 consensus report. Aliment Pharmacol Ther 2002;16:167-80.

2 de Boer WA, Tytgat GN. Search and treat strategy to eliminate Helicobacter pylori associated ulcer disease. Gut 2001;48:567-70.

3 Gaist D, Sorensen HT, Hallas J. The Danish prescription registries. Dan Med Bull. 1997;44:445-8.

4 Frank L. Epidemiology: when an entire country is a cohort. Science 2000;287:2398-9.

5 McColl KE, Dickson A, El-Nujumi A, El-Omar E, Kelman A. Symptomatic benefit 1-3 years after $H$ pylori eradication in ulcer patients: impact of gastroesophageal reflux disease. Am J Gastroenterol 2000;95:101-5.

(Accepted 12 June 2003)
Department of Medical

Gastroenterology, Odense University Hospital, DK-5000, Denmark

Annmarie Lassen senior registrar Jesper Hallas consultant

Department of Internal Medicine, Odense University Hospital

Ove B Schaffalitzky de Muckadell

professor

Correspondence to: A Lassen annmarie.lassen@ ouh.fyns-amt.dk

BMJ 2003;327:603 